\title{
SHPB Test of High-Strength Concrete
}

\author{
Chen LIU ${ }^{1, a^{*}}$, Lan PANG ${ }^{1}$, Wei-Ling CHEN² \\ ${ }^{1}$ Institution of Dachuan Area House, Acquisition in Dazhou, Dazhou635000, China \\ ${ }^{2}$ Housing and Urban-Rural Development, Bureau in Kaijiang, Dazhou635000, China \\ aliuchenchengj@163.com \\ ${ }^{*}$ Corresponding author
}

Keywords: High-strength concrete, SHPB, Impact loading, Strain rate, Stress uniformity.

Abstract. The SHPB of $120 \mathrm{~mm}$ was used to investigate the dynamic mechanical behavior of the high-strength concrete under impact loading.To research the effect of different strength grade (54.82 $\mathrm{MPa}, 63.75 \mathrm{MPa}, 84.00 \mathrm{MPa})$ and different strain rate $(10 \sim 40 / \mathrm{s})$ for the dynamic mechanical properties of concrete, the results show that: It is feasible to research the dynamic mechanical properties of high-strength concrete with the SHPB of $120 \mathrm{~mm}$. the DIF of high-strength concrete can be expressed by the formula. When the strain rate remain the same, With the increase of concrete strength grade, DIF is reduced, The enhancement effect becomes weak.

\section{Introduction}

Concrete is one of most widely used engineering material,it is always in a very important position in engineering construction. Over the past decade, because of increasing terrorist explosion event, structure under impact or blasting dynamic load ability has been paid more and more attention, the dynamic characteristics of concrete gained wider attention. Past research is more on the static mechanical properties of concrete, there are few breakthroughs on the dynamic mechanical properties of concrete in the last 20 years [1-2]. Although some related research have made a lot of achievement at home and abroad in recent years, but as the result of test equipment, method, type of specimen and loading rate or ways, it also has much different.

Now, the split Hopkinson pressure bar (SHPB) is considered to the most effective way to measure the dynamic characteristics of Solid materials under $10 \sim 10^{3} / \mathrm{s}$ strain rate. In SHPB experiment assumes that the internal stress of specimen is equal everywhere; it means the specimen is as small as possible; However, material uniformity of the specimen require the concrete specimen is large enough. the diameter of compressive bar is usually greater than $50 \mathrm{~mm}$, which commonly used in the study of concrete material, and in China commonly uses a diameter of $74 \mathrm{~mm}$ and $100 \mathrm{~mm}$ [3].

\section{Test Equipment and Specimens Fabricating}

The experiment uses big radial size split Hopkinson device, the diameter of pressure bar is $120 \mathrm{~mm}$, the length is $4000 \mathrm{~mm}$.the diameter of bullet is also $120 \mathrm{~mm}$, which length is $600 \mathrm{~mm}$. The material of bullet and pressure bar is Aluminum/LY12CZ..its elastic modulus ,yield Strength and ultimate strength are $71 \mathrm{GPa}, 300 \mathrm{MPa}$ and $460 \mathrm{MPa}$. The SHPB device is shown in figure 1 .

Tab.1 The mixing ratio of concret

\begin{tabular}{ccccc}
\hline $\begin{array}{c}\text { Design } \\
\text { strength }\end{array}$ & $\begin{array}{c}\text { Cement } \\
\left(\mathrm{kg} / \mathrm{m}^{3}\right)\end{array}$ & $\begin{array}{c}\text { Water } \\
\left(\mathrm{kg} / \mathrm{m}^{3}\right)\end{array}$ & $\begin{array}{c}\text { Fine } \\
\text { aggregate } \\
\left(\mathrm{kg} / \mathrm{m}^{3}\right)\end{array}$ & $\begin{array}{c}\text { Coarse } \\
\text { aggreg } \\
\text { ate } \\
\left(\mathrm{kg} / \mathrm{m}^{3}\right. \\
)\end{array}$ \\
\hline A & 300 & 210 & 560 & 1192 \\
B & 410 & 210 & 625.5 & 1163.3 \\
C & 540 & 195 & 612 & 1138 \\
\hline
\end{tabular}




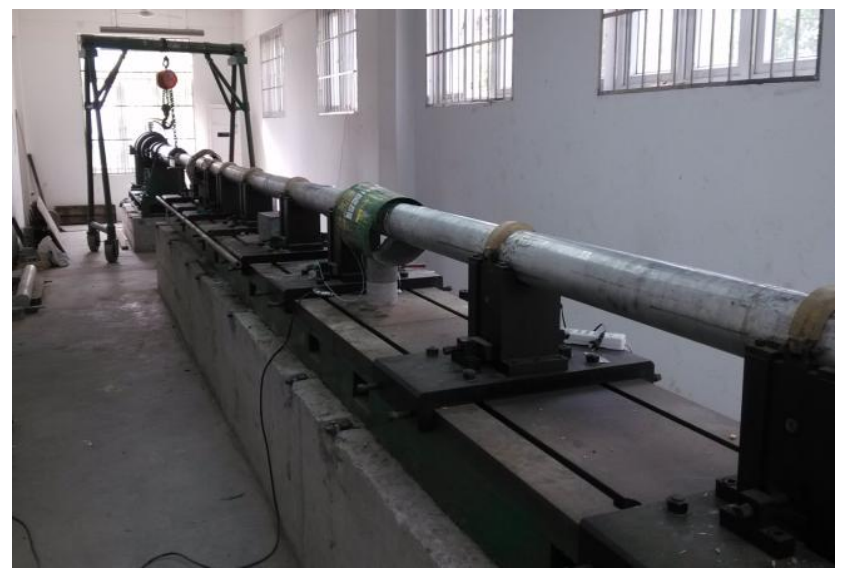

Fig.1 The SHPB device

Concrete specimens are divided as A, B, C. Cement use 42.5 Portland cement, fine aggregate use natural sand,coarse aggregate use broken stone,gradation continuous. According the GB/T50081-2002 [4] to make specimens, the specimen is a Cylinder with $\varphi 117 \times 80 \mathrm{~mm}$. The mixing ratio of different concrete are shown in table 1.

\section{Experiment Content and Data Processing Method}

In the paper, The researchers study the strength grade of concrete specimen of the effect of dynamic mechanical properties, carrying out the quasi-static compression test and the dynamic impact test. Measured A, B, C group of cylindrical specimens of the static ultimate strength is respectively 54.82 $\mathrm{MPa}, 63.75 \mathrm{MPa}, 84.00 \mathrm{MPa}$. the dynamic impact test uses big radial size split Hopkinson device to carry out different strain rate (10 40/s) different initial strength of concrete impact compression test.

The basic principle of SHPB experimental technology is one dimension elastic stress wave theory[5]. Through the Strain Gauge pasted on the incident bar and transmission bar to collect the waveform signal $\varepsilon_{i}(t), \varepsilon_{r}(t), \varepsilon_{t}(t)$. Based on one dimensional stress wave theory, Specimens of the average stress, strain and strain rate can express as:

$$
\begin{aligned}
& \sigma_{s}(\mathrm{t})=E A\left[\varepsilon_{i}(t)+\varepsilon_{r}(t)+\varepsilon_{t}(t)\right] / 2 A_{s} \\
& \varepsilon_{s}(t)=C_{o} \int_{0}^{t}\left[\varepsilon_{i}(t)-\varepsilon_{r}(t)-\varepsilon_{t}(t)\right] d t / l_{s} \\
& \dot{\varepsilon}_{s}(t)=C_{o}\left[\varepsilon_{i}(t)-\varepsilon_{r}(t)-\varepsilon_{t}(t)\right] / l_{s}
\end{aligned}
$$

The above method is referred to the "three-waves" method. the E,A are elastic modulus and area of the pressure bar. ${ }^{l}, A_{s}$ are the concrete's length and cross section. $\varepsilon_{i}(t), \varepsilon_{r}(t), \varepsilon_{t}(t)$ mean the strain producted by incident wave, reflected wave and transmission wave, which are measuring by strain gauge.

\section{The Experimental Results and Analysis}

Using big radial size split Hopkinson pressure bar study the dynamic mechanical properties of concrete, it need to consider the influence of wave propagation to analysis the credibility of the experimental results. The uniformity of internal stress of specimen is the necessary conditions to ensure the effectiveness and reliability of the SHPB impact compression experiment. Some experimental results are shown in table 2 . 
Tab.2 Some experimental results.

\begin{tabular}{lcccccc}
\hline ID & $p$ /Mpa & $\mathrm{V}(\mathrm{m} / \mathrm{s})$ & $\sigma / \mathrm{MPa}$ & $\varepsilon / \%$ & $\overline{\dot{\varepsilon}} / \mathrm{s}^{-1}$ & $\dot{\varepsilon}_{\text {max }} / \mathrm{s}^{-1}$ \\
\hline $\mathrm{A} 1$ & 0.15 & 12.80 & 58.07 & 0.61 & 18.43 & 26.50 \\
$\mathrm{~A} 2$ & 0.16 & 11.89 & 58.83 & 0.58 & 17.00 & 19.76 \\
$\mathrm{~A} 3$ & 0.16 & 14.58 & 59.08 & 0.48 & 15.51 & 16.56 \\
$\mathrm{~A} 4$ & 0.15 & 20.21 & 71.24 & 0.45 & 30.09 & 38.21 \\
$\mathrm{~B} 1$ & 0.17 & 18.62 & 72.00 & 0.49 & 20.85 & 33.00 \\
$\mathrm{~B} 2$ & 0.17 & 17.62 & 67.70 & 0.53 & 16.54 & 19.50 \\
$\mathrm{~B} 3$ & 0.17 & 15.28 & 69.58 & 0.49 & 17.16 & 22.72 \\
B4 & 0.15 & 22.74 & 77.88 & 0.53 & 33.05 & 46.28 \\
$\mathrm{C} 1$ & 0.20 & 14.22 & 86.56 & 0.47 & 17.45 & 34.25 \\
$\mathrm{C} 2$ & 0.21 & 15.25 & 87.80 & 0.57 & 21.20 & 34.97 \\
$\mathrm{C} 3$ & 0.21 & 13.26 & 93.74 & 0.57 & 22.34 & 38.90 \\
$\mathrm{C} 4$ & 0.20 & 20.85 & 100.55 & 0.42 & 31.36 & 50.45 \\
\hline
\end{tabular}

The Uniformity of the Stress. Generally, the concrete is treated as a isotropic uniform material, but concrete are not an uniformly plastid, there are many initial defects inside the concrete. It contributes to energy attenuation of the stress wave in the process of transmission, and leads to energy dissipation when the stress wave occurs reflection and transmission at the weak surface ${ }^{[6]}$. At the same time because of the difference of wave impedance between concrete specimen and wave-guiding rod leads to that the imposed stress don't agree with each other around two end face of the specimens. So, in the analysis of the dynamic mechanical property, the effect of the inconsistency should be considered ${ }^{[7-8]}$.

In SHPB experiments, when the incident pulse arrive at the specimen, it gets into loading process, to ensure that the stress is uniformity before the destruction of specimen can satisfy the hypothesis of the SHPB system.

Establish stress uniformity coefficient $\alpha$ as the evaluation index of stress uniformity in the SHPB experiment.

$$
\alpha=\frac{\int_{0}^{T}\left(\varepsilon_{i}+\varepsilon_{r}\right) \mathrm{dt}}{\int_{0}^{T}\left(\varepsilon_{t}\right) \mathrm{dt}}
$$

The " $T$ " means the action time of stress wave. when the $\alpha$ is equal to " 1 ", the stress of specimen is nearly the same on both ends. Taking "C1" for example, analyzed the stress uniformity of specimen in the process of SHPB experiment. The time history curve of stress uniformity coefficient is shown in figure 2 .

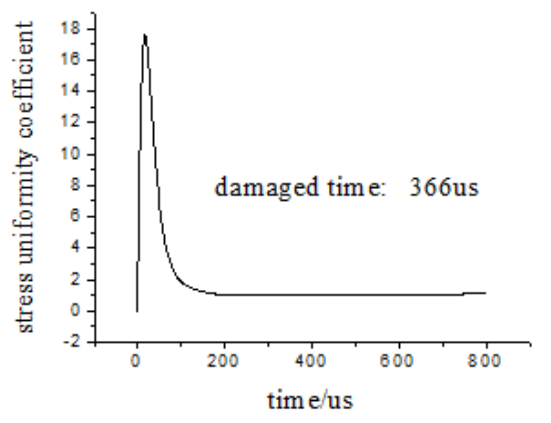

Fig.2 The time history curve of stress uniformity coefficient

From the figure, before the concrete is damaged, the stress uniformity coefficient has been stable near " 1 ", the stress on both ends of the specimen is basically the same, show that the stress state of specimen is uniformly. The experiment meet the stress uniformity hypothesis.

Strength Characteristics. According to the experimental results, the relationship of the " $A$ " specimens' compressive strength and strain rate is shown in figure 3.from the figure, with the increase of strain rate, the ultimate strength of concrete has an good increasing relationship.the " $\mathrm{B}$ " and " $\mathrm{C}$ " also have the same regular. However, In the study of the relationship between concrete strength and 
strain rate, people are more interested in the improvement of dynamic strength relative to the static strength values under a particular strain rate.

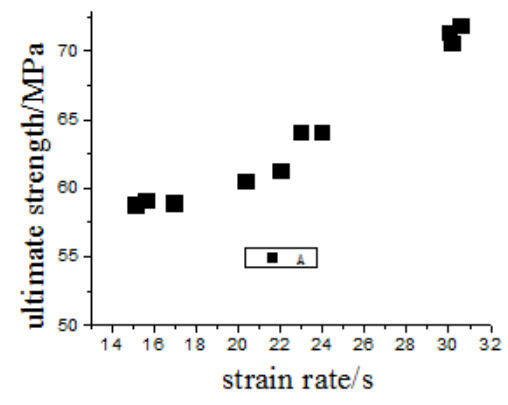

Fig.3 The relationship of compressive strength with strain rate

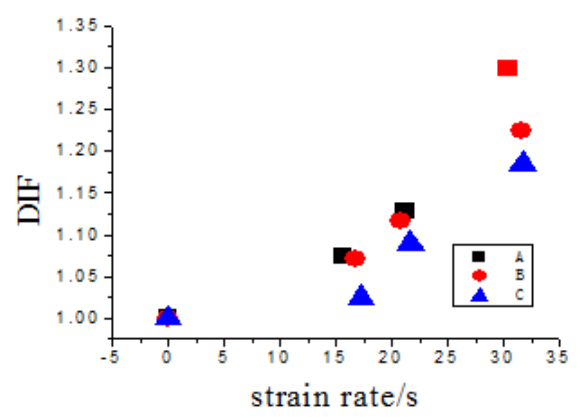

Fig.4 The relationship of DIF with strain rate.

Define DIF ,it means the ratio of the dynamic compressive strength of concrete and static compressive strength, reflecting the growth ability of material compressive strength under the impact load. The figure 4 is the relationship of different strength concrete's DIF with strain rate. The experimental results show that, with the increase of strain rates ,the DIF of different strength grade concretes increase, the dynamic compressive strength of concrete and the DIF have great correlation with its own strength. When the strain rate remain the same, with the increase of concrete strength grade, DIF is reduced; with the increase of their own strength, the dynamic compressive strength keeps increase ,but DIF is reduced. The enhancement effect becomes weak ,that if the strain rate improves, the compressive strength would increase.
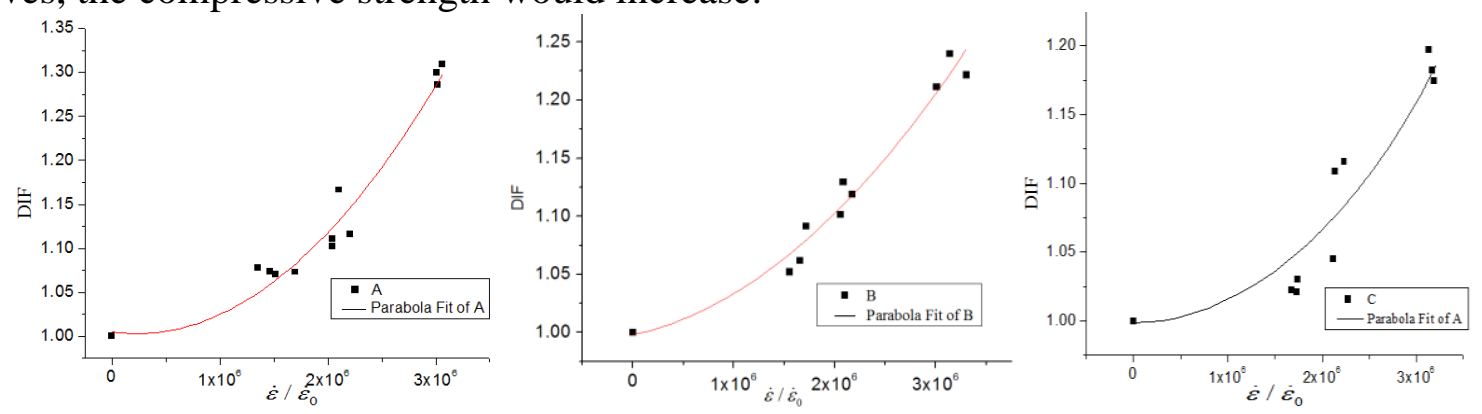

Fig.5 The fitting result of DIF- strain rate

Fitting to the experimental results, the empirical formula of DIF and strain rate are as follow:

$$
D I F=a+b \cdot\left(\dot{\varepsilon} / \dot{\varepsilon}_{0}\right)+\mathrm{c} \cdot\left(\dot{\varepsilon} / \dot{\varepsilon}_{\mathrm{O}}\right)^{2}
$$


$\dot{\varepsilon}$ is the experimental strain rate; $\dot{\varepsilon}_{o}$ is the reference strain rate, suggest to take $10-5 / \mathrm{s} ; \mathrm{a}, \mathrm{b}$ and c are constant; The fitting parameters of different initial strength concrete are shown in table 3 . The fitting result is shown in figure 5 .

Tab.3 The fitting parameters of different initial strength concrete

\begin{tabular}{lllll}
\hline $\begin{array}{l}\text { Strengh } \\
\text { grade }\end{array}$ & $\mathrm{a}$ & $\mathrm{b}$ & $\mathrm{c}$ & $\mathrm{R}$ \\
\hline $\mathrm{A}$ & 1.000 & $-1.424 \mathrm{E}-8$ & $3.691 \mathrm{E}-14$ & 0.973 \\
$\mathrm{~B}$ & 0.996 & $1.867 \mathrm{E}-8$ & $1.886 \mathrm{E}-14$ & 0.960 \\
$\mathrm{C}$ & 0.997 & $2.003 \mathrm{E}-8$ & $1.649 \mathrm{E}-14$ & 0.920 \\
\hline
\end{tabular}

Failure Mode. The damage of concrete is the result of the interaction between many micro-crack inside the concrete, the failure mode reflects the concrete stress, therefore there is of great significance to analyze it. The destruction of the different strength of concrete under different strain rate are shown in figure 6.According to the figure 6, concrete show different failure mode under different strain rate, while the strain rate keeps the same, different strength grade concrete specimens have the same failure pattern. When the strain rate is low(about 10/s), firstly the concrete is cracking from surrounding ; with the strain rate increases, cracks gradually extend to the center, deepens the fragmentation degrees ,specimen damage into squares, When the strain rate is further increasing, concrete specimens become grinding. it is almost consistent with Huiying Wang 'numerical simulation ${ }^{[9]}$.

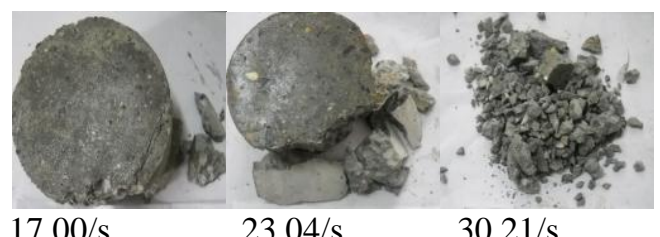

(A)

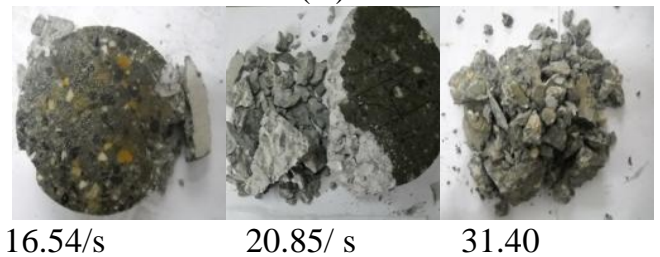

(B)

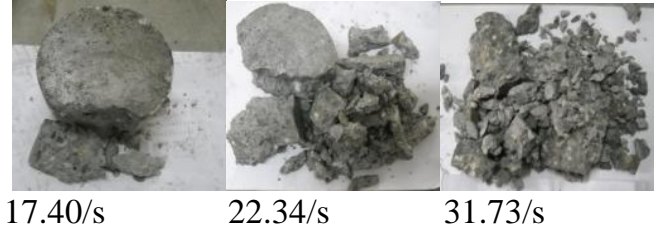

(C)

Fig.6 The destruction of concrete

\section{Conclusion}

After the experiment and analysis, the paper mainly obtained the following conclusions:

(1) It is feasible to research the dynamic mechanical properties of high-strength concrete with the SHPB of $120 \mathrm{~mm}$.

(2) The dynamic compressive strength of concrete and the DIF have great correlation with its own strength. When the strain rate remain the same, With the increase of concrete strength grade, DIF is reduced, the enhancement effect becomes weak.

(3) While the strain rate keeps the same, different strength grade concrete specimens have the same failure pattern. 


\section{References}

[1] Hu Shi sheng, Wang Daorong. Dynamic Constitutive Relation of Concrete under Impact[J]. Explosion and Shock Waves. 2002, 22(3):242-246.

[2] T Tang, L EMalvern, D AJenkins. Rate effects in uniaxial dynamic compression of concrete [J].J.EngMech,1922, 118(1):108-124.

[3] Zhang Zhi gang, Kong Da qing. Dynamic mechanical behavior of concrete under high strain rate using SHPB[J]. Journal of PLA University of Science and Technology. 2007,8(6):611-617.

[4] GB/T50081-2002,Standard for test method of mechanical properties on ordinary concrete[s].

[5] Ravichandran G, Subhash G. Critical appraisal of limiting strain rates for compression testing ceramics in a split Hopkinson pressure bar [J]. Journal American Ceramic Society, 1994. 77(1): 263-267.

[6] Li Xibing Influence of the structural weakness planes in rock mass on the propagation of stress waves[J]. Explosion and Shock Waves. 1993, 13(4):334-341.

[7] Xu Mingli, Zhang Ruoqi, Zhang Guangying. Analysis of early stage specimen stress equilibrium in SHPB experiment[J]. Explosion and Shock Waves. 2003, 23 (5):235-240.

[8] Song bo, Song Li, Hu Shisheng. Coupling solved method of SHPB experimental data processing[J]. Explosion and Shock Waves. 1998, 18(2):167-171.

[9] Wang Huiying. Study on Numerical Simulation of SHPB Test of High-strength Concrete[J]. Earthquake Resistant Engineering and Retrofitting. 1998, 18(2):167-171. 